\title{
Perioperative pulmonary complications: can they be predicted and minimized?
}

\author{
Yamuna Rajapakse ${ }^{1}$, Lakmali Amarasiri ${ }^{2}$ \\ ${ }^{1}$ Department of Anatomy, Faculty of Medicine, University of Colombo \\ ${ }^{2}$ Department of Physiology, Faculty of Medicine, University of Colombo
}

Keywords: Perioperative; pulmonary; COVID-19

\begin{abstract}
Patients undergo surgery for various reasons. A main concern for the surgeon and anaesthetist is the occurrence of pulmonary complications during and after surgery. Perioperative pulmonary complications are more frequent in patients with compromised pulmonary function. If there is a possibility to predict such complications, necessary precautions could be taken, and the patients could be optimized to ensure that such complications are minimized. A better understanding of the physiological changes and risk factors predisposing to perioperative pulmonary complications is essential to develop strategies for reducing these complications. The resulting reduction in morbidity and mortality would lead to improvement of quality of life and reduced of costs.
\end{abstract}

This article aims to make the surgeon aware of the possible surgery and anaesthesia related physiological derangements, and human and environmental factors in the operating theatre that can contribute to perioperative respiratory complications in patients undergoing surgery that is not directly related to the lungs. It stresses on the importance of actively looking for unseen and underlying physiological, pathological, patient and drug related factors to minimize perioperative pulmonary complications, highlighting important considerations in patients with underlying pulmonary disease.

\section{Introduction}

Annually approximately 300 million people undergo surgery worldwide [1]. Perioperative pulmonary complications are a cause of significant morbidity and mortality with such patients having longer duration of hospital stay. They occur more frequently than cardiac complications [2]. Such complications arise due to patient factors and effects of surgical procedures, anaesthesia, the surgical environment or pharmacological interventions during the procedure [3]. Poor pain relief, sedation and increased ventilatory demands

Correspondence: Yamuna Rajapakse

E-mail: yamunanb@yahoo.com

(iDhttps://orcid.org/0000-0002-5583-2977

Received: 25-03-2021 Accepted: 31-03-2021

DOI: http://doi.org/10.4038/sljs.v39i1.8819 in the cold environment exacerbate these effects $[4,5]$. When the load on the respiratory system exceeds capacity, failure will occur.

The risk for perioperative pulmonary complications depends on the site of surgery and whether it is elective or emergency surgery. The risk increases if the patient has underlying comorbidities and pre-existing pulmonary diseases such as asthma, interstitial lung disease (ILD), chronic obstructive pulmonary disease (COPD) and obstructive sleep apnoea (OSA) and, if the surgical process is directly related to the pulmonary system $[5,6]$. These risks are more in extremes of age, obesity and smokers [5]. Other commonly overlooked risk factors in the 'apparently healthy' are atopy [7] and gastrooesophageal reflux disease (GORD) [8]. The risk of postoperative complications can be reduced by postponement of surgery in patients who have reaspiratory infections or have incompletely treated pulmonary disease or comorbidities [6].

This article provides answers to frequently asked questions regarding perioperative pulmonary complications and also discusses special considerations in patients with respiratory infections including COVID-19 and tuberculosis, OSA and those on long term steroid use.

What are the commonly occurring perioperative pulmonary complications?

These include hypoxaemia, atelectasis, aspiration pneumonitis, bronchospasm, pleural effusion, pneumothorax, pneumonia, exacerbation of pre-existing pulmonary conditions, respiratory infections, pulmonary embolism, acute respiratory distress syndrome and respiratory failure [5, 9].

\section{How does surgery affect pulmonary function?}

Direct or indirect effects of surgery can lead to respiratory muscle dysfunction. Location of surgical incisions, length of the surgery, post-surgical deconditioning, procedures causing neurological damage or dysfunction can lead to respiratory muscle dysfunction, reducing tidal volume (TV), vital capacity (VC), and total lung capacity (TLC) [4, 10]. Insufficient cough and insufficient inspiratory effort due to pain following surgery can lead to atelectasis, reduce 
functional residual capacity and lead to ventilation-perfusion mismatch. Atelectasis is a factor that predisposes to pulmonary infections $[5,11]$. However, procedures such as lung transplantation and lung volume reduction may actually improve the function of the respiratory muscles and oxygenation [12].

Surgeries that are considered as high risk to the patient include thoracic surgery, abdominal surgery (upper more than lower), aortic aneurysm repair, neurological surgery, vascular and head and neck surgeries. Surgery where the duration exceeds two hours and emergency procedures also increase the risk of pulmonary adverse events $[5,13]$.

\section{What are the physiological derangements in pulmonary function that may occur during anaesthesia?}

Physiological derangements are more common during general anaesthesia (compared to regional anesthesia) and with use of long-acting muscle relaxants. Inspiratory capacity and expiratory reserve are reduced and cough efficiency temporarily decreased during high lumbar and thoracic segment blockage [14]. Physiological derangements that arise as a consequence of general anaesthesia are given in table 1. These include effects of intubation, anaesthetic agents and effects attributable to the patient's position during anaesthesia $[5,11,14]$.

\section{How can perioperative pulmonary complications be predicted?}

A thorough preoperative medical history and physical examination combined with investigations are important steps that help identify risk factors associated with perioperative pulmonary complications [13]. Preoperative risk stratification using risk prediction models takes into consideration non-modifiable and modifiable risk factors (based on history and examination), type of surgery and preoperative investigations. ARISCAT (Assess Respiratory Risk In Surgical patients in Catalonia) and PERISCOPE (Prospective Evaluation of a Risk Score for postoperative pulmonary complications in Europe) are such models [5]. However, first time drug allergy or errors in drug administration can very rarely occur during surgery despite thorough preoperative assessment [15].

\footnotetext{
What are the patient-related factors that increase risk of perioperative pulmonary complications?

Important information to be elicited by a thorough medical history is given in table 2, including demographic parameters, symptoms, exposure and habits, exercise capacity, and presence of comorbidities and allergies. Often overlooked conditions such as atopy, wheezing (in childhood, in response to infections or cold) and GORD need to be specifically sought $[5,7,8,13,14]$.
}

What are the important features that should be looked for during physical examination?

A thorough examination of general appearance and the cardiorespiratory system is essential, including measurement of height and weight $[5,13]$. Important features to note are mentioned in table 3 .

What are the investigations that assist in predicting perioperative pulmonary complications? [5, 12, 14]

Table 4 lists investigations that are routinely performed to predict risk of perioperative complications in high risk surgeries and in those with compromised pulmonary sustems $[5,13]$. Prior to performing such investigations, factors such as whether the outcome would influence the decision to postpone or cancel surgery, the risk versus benefit and the cost of the test are taken into consideration.

\section{Do pulmonary function tests (PFTs) need to be performed routinely before surgery?}

Routine spirometry assessment prior to surgery is generally not recommended in non-thoracic surgery or in individuals with no known or suspected pulmonary disease [16]. PFTs in these situations are unlikely to influence the decision whether the surgery should be performed or to alter perioperative management. The guidelines states that even patients who undergo major surgery and who are of American Society of Anesthesiologists (ASA) grade 3 or 4 because of known or suspected pulmonary disease should be tested only after seeking advice from a senior anaesthetist. Such patients are likely to have already undergone investigation or treatment by respiratory specialists. If they have not been assessed, then PFTs should be performed [16].

In surgeries where pulmonary parenchymal resection is planned, PFTs are of value. In pneumonectomy, preoperative spirometry, diffusing capacity (DLCO) and lung perfusion scintigraphy are used to calculate percent predicted postoperative values [12].

What PFTs are commonly performed to predict perioperative pulmonary complications?

Arterial blood gas analysis and oxygen saturation (SPO2) estimation on room air, and spirometry are the most common PFTs to be performed prior to cardiothoracic surgery [12]. Spirometry which measures inhaled and exhaled lung volumes and flow over time, is used to diagnose airway obstruction and restriction and to grade severity in those with suspected pulmonary disease. A postbronchodilator FEV1/FVC ratio of $<70 \%$ on spirometry confirms COPD in a patient with airway obstruction (GOLD criteria) and reversibility indicates asthma [17]. Spirometry is also combined with static lung volumes and DLCO values in risk assessment (table 5) [12]. An abnormal preoperative 
Table 1. Physiological derangements due to general anaesthesia

\begin{tabular}{ll}
\hline Effect of anaesthasia & Physiological derangernent \\
\hline Endotracheal tube, mucosal swelling & increased airway resistance in upper airways \\
\hline Reduced chest wall and diaphragm tone & atelectasis \\
\hline Reduced tone of the upper airway muscles & airway collapse \\
\hline Reduced lung compliance & increased work of breathing \\
\hline Supine or lateral position & reduced tidal volume and functional residual capacity \\
Surgery & early airway closure \\
& V/Q mismatch \\
\hline Sedation from opioids or hypercapnia & Central respiratory depression \\
\hline Prolonged exposure to anaesthetics & Impairment of ventilatory response to hypoxia and hypercapnia and \\
& acidosis \\
Inhibition of hypoxic pulmonary vasoconstriction
\end{tabular}

Table 2. Patient-related factors that increase the risk of perioperative complications

\begin{tabular}{|c|c|}
\hline & Patient factor \\
\hline Physiological factors & Extremes of age and pregnancy \\
\hline Symptoms & $\begin{array}{l}\text { Cough, shortness of breath (at rest and in response to activity), dyspnoea, recent infections (within } \\
1 \text { month) } \\
\text { Daytime sleepiness, snoring, episodes of observed apnoea } \\
\text { Increasing (fluid retention) or decreasing weight (malnutrition/protein } \\
\text { deficiency/>10\% weight loss in the preceding } 6 \text { months) } \\
\text { Cardiac angina }\end{array}$ \\
\hline Exposure & $\begin{array}{l}\text { Pulmonary toxic medications (bleomycin, amiodarone, etc.) } \\
\text { Environmental/occupational contamination (coal dust, secondhand smoke, asbestos, etc.) } \\
\text { Tobacco use/ exposure to secondhand smoke fuel } \\
\text { Alcohol use }\end{array}$ \\
\hline Exercise capacity & $\begin{array}{l}\text { Inability to perform activities of daily living without assistance or live independently } \\
\text { Self- estimate of ability to climb } 2 \text { flights of stairs or walk approximately } 0.4 \text { miles or } 350-400 \mathrm{~m} \text { at a } \\
\text { reasonable pace ( } 3.5 \text { miles } / \mathrm{h} \text { ) without shortness of breath is essential for elective surgery } \\
\text { Features of heart failure }\end{array}$ \\
\hline In the apparently normal & $\begin{array}{l}\text { Atopy (known or suspected), childhood wheezing, allergic rhinitis, } \\
\text { syncopal attacks, gastro oesophageal reflux, exercise or cold induced wheezing or cough }\end{array}$ \\
\hline Allergies & History of known or suspected allergies \\
\hline Comorbidities & $\begin{array}{l}\text { COPD, asthma } \\
\text { Long term steroid use } \\
\text { Congestive heart failure } \\
\text { Metabolic abnormalities Neuromuscular defects } \\
\text { Obstructive sleep apnoea } \\
\text { Obesity } \\
\text { Diabetes mellitus } \\
\text { Hypertension } \\
\text { Malignancies } \\
\text { Chronic liver disease } \\
\text { Renal failure } \\
\text { Endocrine disorders } \\
\text { Pulmonary hypertension }\end{array}$ \\
\hline
\end{tabular}


Table 3. Physical signs to be observed to predict risk of perioperative complications

\begin{tabular}{ll}
\hline General appearance & $\begin{array}{l}\text { Muscle wasting, size of oral opening, visibility of uvula and palate, mobility of } \\
\text { cervical spine, condition of teeth, thyromental distance, neck circumference, } \\
\text { digit clubbing, cyanosis, shape of the thorax }\end{array}$ \\
\hline Height and weight & Body mass index \\
\hline Respiratory system & $\begin{array}{l}\text { A thorough airway examination: respiratory rate and pattern respiratory effort } \\
\text { during conversation and with movement, signs and symptoms of obvious lung } \\
\text { and lung related conditions, diminished respiratory sounds, dullness to } \\
\text { percussion, laryngeal height, } \\
\text { Positive cough test (where the patient coughs involuntarily after deep } \\
\text { inspiration) }\end{array}$ \\
\hline Cardiovascular system & Features of heart failure \\
\hline
\end{tabular}

Table 4. Investigations performed to predict risk of perioperative complications

\begin{tabular}{ll}
\hline Blood tests & Serum eosinophils \\
& Serum total IgE \\
& Blood urea \\
Serum haemoglobin & Serum albumin \\
& Serum creatinine \\
& Liver function tests \\
\hline Radiology & Chest radiograph \\
& Lung computerized tomographic scan (especially High-resolution CT) and MRI are \\
performed only if there is clinical suspicion of a condition that could affect decision- \\
making in the perioperative period
\end{tabular}

Table 5. Spirometry parameters and information obtained useful in assessment of suitability for surgery

\begin{tabular}{ll}
\hline Parameter & \\
\hline Reduced $F V C$, VC or TLC & Indicative of restrictive disease \\
\hline $\begin{array}{l}\mathrm{FEV}_{1} / \mathrm{FVC} \text { ratio }<70 \% \\
\text { and } \mathrm{FEV}_{1}<80 \% \text { of predicted }\end{array}$ & Indicative of obstructive lung disease \\
\hline Post bronchodilator $\mathrm{FEV}_{1} / \mathrm{FVC}$ ratio of $<0.70$ & Diagnostic of COPD \\
\hline $\begin{array}{l}\text { Obstructive spirometry values and } \\
\text { reduced DLCO }\end{array}$ & Indicative of emphysema \\
\hline Maximal voluntary ventilation & $\begin{array}{l}\text { To assess exercise tolerance } \\
\text { and respiratory muscle endurance }\end{array}$ \\
\hline Flow volume loops* & $\begin{array}{l}\text { To evaluate airway obstruction } \\
\text { To differentiate between fixed and variable } \\
\text { (intra- and extra thoracic) obstruction }\end{array}$ \\
\hline
\end{tabular}

FVC, Forced Vital Capacity VC, Vital Capacity TLC, Total Lung Capacity

$\mathrm{FEV}_{1}$, Forced Expiratory Volume in the first second of FVC

$\mathrm{FEV}_{1} / \mathrm{FVC}$, Ratio of $\mathrm{FEV}_{1}$ to $\mathrm{FVC}$

DLCO, Diffusing Capacity of the Lung for Carbon Monoxide

*These can be helpful in the workup of patients with unexplained dyspnoea, stridor, suspected tracheal stenosis and vocal cord pathology 
Table 6. Protocol for the preoperative objective assessment of COVID-19 survivors, stratified

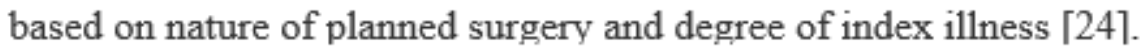

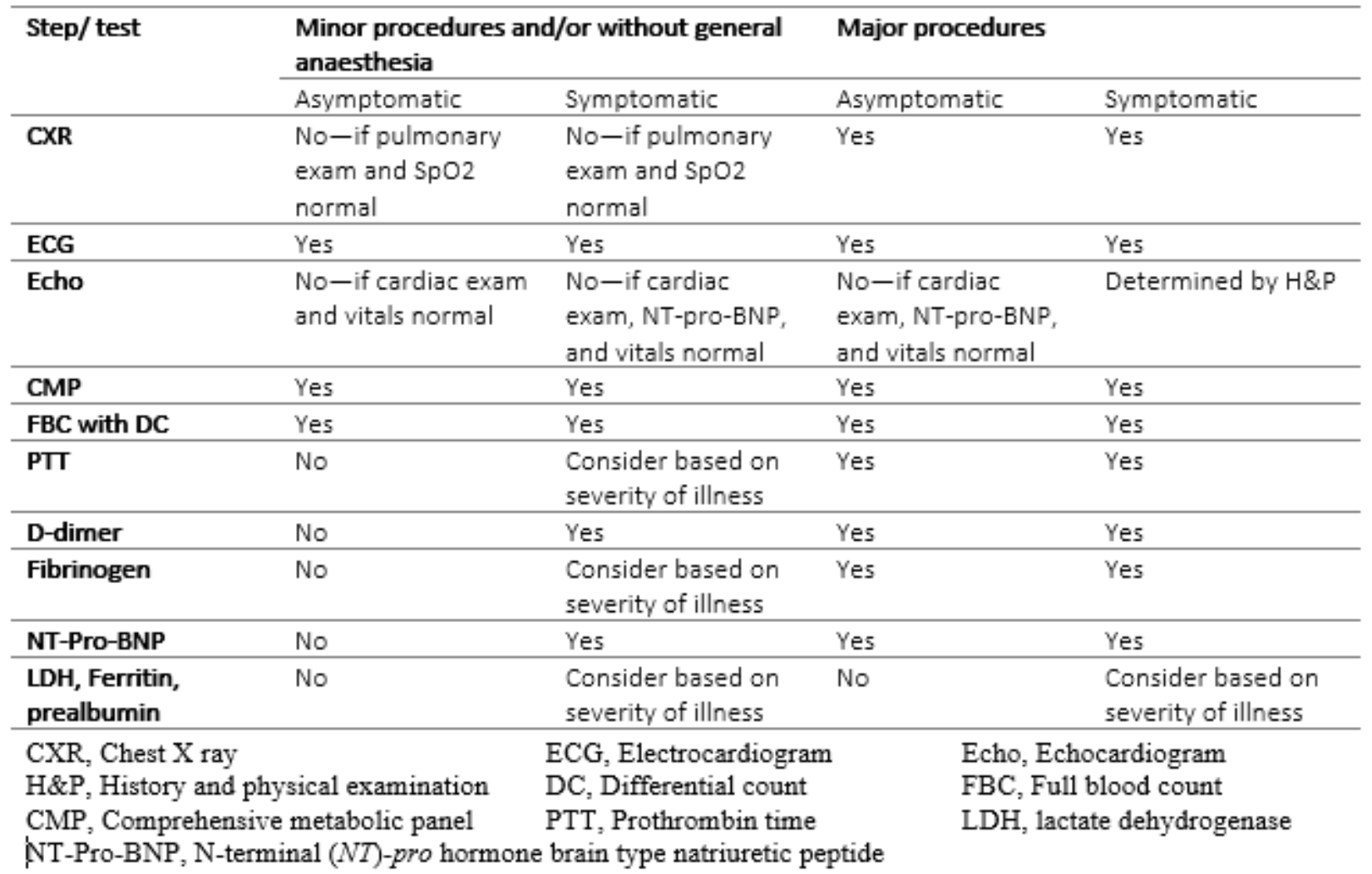

Table 7. Perioperative steroid management in patients on high doses of steroids for interstitial lung disease or sarcoidosis, requiring surgery [34]

\begin{tabular}{|c|c|c|}
\hline & Intra-operative steroid replacement & Postoperative steroid replacement \\
\hline \multirow[t]{2}{*}{ Major surgery } & $\begin{array}{l}\text { Hydrocortisone } 100 \mathrm{mg} \text { intravenously at } \\
\text { induction, followed by immediate } \\
\text { initiation of a continuous infusion of } \\
\text { hydrocortisone at } 200 \mathrm{mg} .24 \mathrm{~h}-1 \text {; }\end{array}$ & $\begin{array}{l}\text { Hydrocortisone } 200 \mathrm{mg} .24 \mathrm{~h}-1 \text { by iv infusion } \\
\text { while nil by mouth (alternatively, } \\
\text { hydrocortisone } 50 \mathrm{mg} \text { every } 6 \mathrm{~h} \text { by im } \\
\text { injection) }\end{array}$ \\
\hline & $\begin{array}{l}\text { Alternatively, dexamethasone } 6-8 \mathrm{mg} \\
\text { intravenously, if used, will suffice for } 24 \mathrm{~h}\end{array}$ & $\begin{array}{l}\text { Resume enteral glucocorticoid at double the } \\
\text { pre-surgical therapeutic dose for } 48 \mathrm{~h} \text { if } \\
\text { recovery is uncomplicated. Otherwise continue } \\
\text { double oral dose for up to a week }\end{array}$ \\
\hline \multirow[t]{2}{*}{$\begin{array}{l}\text { Body surface and } \\
\text { intermediate } \\
\text { surgery }\end{array}$} & $\begin{array}{l}\text { Hydrocortisone } 100 \mathrm{mg} \text {, intravenously at } \\
\text { induction, followed by immediate } \\
\text { initiation of a continuous infusion of } \\
\text { hydrocortisone } 200 \mathrm{mg} .24 \mathrm{~h}-1\end{array}$ & $\begin{array}{l}\text { Double regular glucocorticoid dose for } 48 \mathrm{~h} \text {, } \\
\text { then continue usual treatment dose if } \\
\text { uncomplicated }\end{array}$ \\
\hline & $\begin{array}{l}\text { Alternatively, dexamethasone } 6-8 \mathrm{mg} \\
\text { intravenously, if used, will suffice for } 24 \mathrm{~h}\end{array}$ & \\
\hline $\begin{array}{l}\text { Bowel procedures } \\
\text { requiring }\end{array}$ & \multicolumn{2}{|c|}{ Continue normal glucocorticoid dose. Equivalent iv dose if prolonged nil by mouth } \\
\hline laxatives/enema & \multicolumn{2}{|c|}{$\begin{array}{l}\text { Treat as per primary adrenal insufficiency if concerned about hypothalamo-pituitary-adrenal } \\
\text { axis function, and risk of adrenal insufficiency }\end{array}$} \\
\hline \multirow[t]{2}{*}{$\begin{array}{l}\text { Labour and } \\
\text { vaginal delivery }\end{array}$} & \multicolumn{2}{|c|}{$\begin{array}{l}\text { Hydrocortisone } 100 \mathrm{mg} \text { intravenously at onset of labour, followed by immediate initiation of } \\
\text { a continuous infusion of hydrocortisone } 200 \mathrm{mg} \cdot 24 \mathrm{~h}-1\end{array}$} \\
\hline & \multicolumn{2}{|c|}{$\begin{array}{l}\text { Alternatively, hydrocortisone } 100 \mathrm{mg} \text { intramuscularly followed by } 50 \mathrm{mg} \text { every } 6 \mathrm{~h} \\
\text { intramuscularly }\end{array}$} \\
\hline
\end{tabular}


spirometry result alone should not deter patient from undergoing planned surgery. In such an event, assessment of risks versus benefits in consultation with relevant specialists should be done [16].

What are the other PFTs that are useful in pre-operative assessment in a patient with known or suspected pulmonary disease?

Static lung volumes are useful to detect hyperinflation of the chest in patients with COPD and DLCO helps to differentiate intrinsic from extrinsic restrictive (neuromuscular, chest wall and pleural) disease. Exercise tests such as six-minute walk test (6MWT), incremental shuttle test and cardiopulmonary exercise testing (CPET) assess the exercise capacity of an individual and indicate the physiological cardiorespiratory reserve that may be available after surgery. Maximal inspiratory and expiratory pressures (MIPs and MEPs) and sniff nasal inspiratory pressure (SNIP) are useful in assessment of respiratory muscle function. Bronchial challenge tests such as bronchoprovocation and exercise challenges are useful to detect compromised lung function in those with normal PFTs, yet with high clinical suspicion. For those who require air travel for surgery, it would seem prudent to assess fitness to fly $[5,6,12]$.

How can perioperative pulmonary complications be minimized?

The following perioperative care interventions are carried out in clinical practice $[3,5,6,7,8,14,18]$, though some lack best quality evidence regarding reducing complications [18].

\section{Box 1: Pulmonary function test parameters and reference values that indicate low risk for perioperative pulmonary complications $[5,6,12,13,16]$ \\ $\mathrm{FEV}_{1} / \mathrm{FVC}$ or $\mathrm{FEV}_{1} / \mathrm{VC}>80 \%$ \\ FVC or VC $>80 \%$ with $<20 \%$ fall when subject lies supine FEV $>80 \%$ \\ MVV $>50 \%$ \\ DLCO $>=70 \%$ \\ $\mathrm{MIP}$ and $\mathrm{MEP}>80 \mathrm{~cm} \mathrm{H} 2 \mathrm{O}$ \\ SNIP $>70 \mathrm{~cm} \mathrm{H} 20$ \\ $\mathrm{SpO} 2>95 \%$ \\ $\mathrm{VO}_{2} \max <20 \mathrm{ml} / \mathrm{kg} / \mathrm{min}$ \\ Desaturation $<4 \%$ with exercise}

\section{Before surgery}

Identification of the "high-risk" patient

Preoperative optimization of comorbidities and respiratory infections

Optimal treatment for COPD, asthma, bronchiectasis and interstitial lung disease

Preoperative bronchodilator therapy in those with a $\mathrm{FVC}<1$ $\mathrm{L}$ or a $\mathrm{FEV} 1<500 \mathrm{~cm} 3$, especially if improvement occurs after treatment.

Perioperative steroid management

Smoking cessation (at least 8 weeks prior to elective surgery)

Correction of anaemia

Preoperative respiratory muscle training

\section{At the time of surgery}

Adequate analgesia

Appropriate management of neuromuscular blocking drugs

Routine use of warming techniques

Intraoperative PEEP, ventilation regimes

Extubation in a sitting up posture (where possible)

Intraoperative use of antiemetics and prokinetics

\section{After surgery}

Early commencement of chest physiotherapy and steam inhalation

Oral hygiene

Early mobilization

Adequate pain relief

Appropriate fluid resuscitation and fluid balance

Continuation of patient's usual inhaler medication with added nebulizer as needed

Postoperative respiratory support with CPAP and nasal highflow oxygen where required.

Is preoperative respiratory muscle training useful in prevention of postoperative pulmonary complications?

Improving respiratory muscle strength in patients undergoing thoracic surgery is beneficial, though there is limited effect on sustained ventilation and maximal oxygen consumption. Intermittent positive pressure breathing, incentive spirometry and deep breathing exercises are commonly utilized to prevent pulmonary complications after thoracic surgery [5, 6$,$] .$

How soon after respiratory infections can surgery be planned?

A patient with recent or ongoing upper or lower respiratory tract infection poses a dilemma in terms of timing of elective and emergency surgery. An upper respiratory tract infection (URI) in adults in the month before surgery was found to be have negative impact on postoperative outcome [19, 20], through either local or systemic effects.

Respiratory tract infections may make even normal individuals susceptible to laryngospasm, bronchial hyperreactivity and bronchospasm, on exposure to anaesthetic gases or produce increased amounts of respiratory secretions for as long as 4-6 weeks after the infectious episode [19]. These patients are more prone to hypoxaemia, atelectasis, 
collapse and pulmonary oedema increasing the risk of perioperative pulmonary complications [19]. Furthermore, a recent history of pneumonia was found to increase postoperative morbidity and mortality significantly when considering a variety of different surgical settings and patient groups [20]. In the case of general surgery, vascular surgery and thoracic surgery, special consideration needs to be given as these surgical types were reportedly most affected by preoperative pneumonia within a 30-day period [20]. Patients with acute lung infections should be adequately treated and postponement of elective surgery seriously considered until symptoms and lung function are back to acceptable levels [19, $20]$.

If an earlier date is required, the patient needs to be investigated similar to a known patient with asthma/ bronchospasm. Sputum cultures need to be negative prior to performing PFTs, however, 6MWT is adequate to assess fitness for surgery if sputum is unavailable. In the patient requiring emergency surgery, however, it was found that in the case of preoperative pneumonia, emergency surgery showed only a mild increase in mortality [20]. The complications arising from increased airway reactivity can be minimized by using laryngeal mask airway (LMA) as an alternate technique to intubation, though it can still produce epiglottic irritation [21]. However, if intubation is mandatory, several options are available. The main treatment option advised is inhalation of sympathomimetics such as salbutamol [22]. Sympathomimetics produce more rapid and effective bronchodilation than the intravenous methylxanthine, aminophylline. Intravenous lignocaine (1.5-2 $\mathrm{mg} / \mathrm{kg}$ ), hydrocortisone $(4 \mathrm{mg} / \mathrm{kg}$ ) or glycopyrrolate $(1 \mathrm{mg}$ ) has also been employed with good effect to help in reversing any reflex response to bronchoconstriction [22].

\section{What is the optimal length of time between recovery from COVID-19 and elective surgery that would minimize perioperative complications?}

A patient diagnosed with COVID-19 should be evaluated in regard to optimizing their medical conditions and physiologic status, if planning for surgery. Since COVID-19 has been found to affect multiple major organ systems, the timing of surgery after a diagnosis of COVID-19 is most important especially when considering the risk of peri-operative complications. Infection with COVID-19 that may have affected the lung parenchyma will manifest as restrictive lung disease and requires specific evaluation prior to planning surgery. Table 6 shows the protocol for objective preoperative assessment of COVID-19 survivors, based on the nature of surgery and degree of illness [23].

Given the current knowledge on the disease, the times to plan surgery after recovery from COVID-19 can be reasonably estimated. The following time periods have been proposed as per literature to schedule elective surgery in patients diagnosed with and recovered from COVID-19 [23].

- Patient asymptomatic or recovered from only, mild respiratory symptoms - four weeks.

- Patient with respiratory symptoms not requiring admission-six weeks.

- Patient who has symptoms and is diabetic, immunocompromised and was hospitalized - eight to ten weeks.

- Patient who was managed in the ICU due to COVID 19 infection-twelve weeks.

The perioperative risk assessment should be individualised and factor in the type of surgery, patient comorbidities and benefit versus risk of delaying surgery [23]. Persisting symptoms, even 60 days beyond the diagnosis, such as breathlessness, fatigue and chest pain are common post COVID 19 infection. Furthermore COVID 19 may have long term effects on cardiac and respiratory function. Recovered COVID-19 patients with residual symptoms, therefore, should undergo a more thorough preoperative evaluation with special attention to the cardiopulmonary systems [24]

.In COVID-19 positive patients requiring emergency surgery, it is better to have a low threshold for intubation, especially in those who have acute respiratory failure. This should bypass non-invasive ventilation techniques (CPAP or BiPAP). This will minimize transmission risks [25]. Awake intubation techniques should be avoided. Procedures that may generate aerosolized particles have been associated with increased coronavirus transmission: eg. non-invasive ventilation, tracheal intubation, tracheostomy, and manual ventilation before intubation and bronchoscopy. An FFP3 mask should therefore be worn by all health care staff who are required to work in close proximity to the patient during these procedures [25].

\section{What is the impact of pulmonary tuberculosis (PTB) on perioperative pulmonary complications in non-chest surgeries?}

Patients with PTB are reported to have a higher risk of perioperative complications compared to those without. These include, pneumonia, septicaemia and pulmonary embolism. Overall complications were also found to be higher [26]. Preoperative PTB was further associated with increased 30day postoperative mortality, a prolonged hospital stay and increased rate of admission to intensive care units [26]. The reasons for this include the effects of PTB on pulmonary inflammation, altered innate immunity and complex drug interactions with anti TB medication [26]. 
When planning surgery for patients with PTB, a respiratory physician's opinion is invaluable. Patients with PTB become non-infectious at two weeks of anti-tuberculous treatment (ATT). After commencing treatment for PTB, sputum is examined for acid fast bacilli (AFB) and Mycobacterium tuberculosis (MTB) culture at two months when sputum smear conversion is expected [27]. Ideally, non-chest surgery, if elective, should be planned for after two months of commencing ATT $[26,27]$.

In the case of emergency surgery, a preoperative 6MWT in patients who are able, or oxygen saturation and $\mathrm{ABG}$ in patients who cannot perform 6MWT, is ideal as PFTs are contraindicated owing to PTB infection. Risk to the operating staff can be minimized by performing sputum AFB and rapid MTB culture as soon as surgery is planned, and by using personal protective equipment (PPE) and negative pressure environment for surgery $[26,27]$.

\section{What is the effect of OSA on perioperative pulmonary complications?}

Patients with OSA have a higher risk of perioperative pulmonary complications. Anaesthetic medication, opioids and other sedatives increase airway obstruction and hypoventilation, which in turn lead to hypercapnic respiratory failure [28]. Patients with OSA have an increased risk of being intubated postoperatively and a several-fold higher risk of being mechanically ventilated than those without OSA [28, 29]. There is also a higher risk of postoperative complications and admission to ICU as well as longer hospital stays than in those without OSA [29, 30].

OSA is generally undiagnosed, therefore, the use of the STOP-BANG questionnaire has been advised for preassessment screening. Depending on the results, the patient may either be referred for sleep studies and started on definitive management or recommended an alternative anaesthetic regime, for example, by using opioid sparing anaesthetic techniques and enhanced monitoring. This screening is recommended by the association of anaesthetists in the UK for all obese patients undergoing surgery [31]. Studies on obese OSA patients undergoing bariatric surgery have shown that such screening and management has improved post-surgical outcome including reduction in postoperative intensive care [28]. Screening also can predict susceptible patients who are either undiagnosed or who are resistant to continuous positive airway pressure treatment, thus enabling more intensive perioperative monitoring [28].

\section{What is the perioperative steroid management in a patient on high doses of steroids for interstitial lung disease or sarcoidosis, requiring surgery?}

Hypothalamo-pituitary adrenal axis (HPAA) suppression has been seen in patients who take doses of prednisolone that exceed $5 \mathrm{mg} / \mathrm{d}$ long term, 7.5-10 mg/d for 1 month or $20 \mathrm{mg} / \mathrm{d}$ for 3 weeks It is also seen in patients taking high doses of other inhaled corticosteroids for a variety of conditions [32]. Patients on such high doses of steroids at the time of planning for surgery require supplementation of corticosteroids in doses that should reflect the physiologic response of the normal adrenal gland to surgical stress. This supplementation should be for only a very short duration. Table 7 describes the perioperative steroid dosing recommendations based on the type of surgery $[33,34]$.

\section{Conclusion}

Perioperative pulmonary complications are common and more evident in those with compromised pulmonary function or undergoing surgery related to the pulmonary system. Knowledge of physiological derangements during surgery and anaesthesia, awareness and anticipation of human and environmental risk factors coupled with risk prediction and correction of modifiable risk factors could help minimize such complications.

All authors disclose no conflict of interest. The study was conducted in accordance with the ethical standards of the relevant institutional or national ethics committee and the Helsinki Declaration of 1975, as revised in 2000 .

\section{References}

1. Weiser TG, Haynes AB, Molina G, Lipsitz SR, Esquivel MM, Uribe-Leitz T, Fu R, Azad T, Chao TE, Berry WR, Gawande AA. Estimate of the global volume of surgery in 2012: an assessment supporting improved health outcomes. Lancet. 2015 Apr 27;385 Suppl 2:S11. doi: 10.1016/S0140-6736(15)60806-6.

2. Gupta S, Fernandes RJ, Rao JS, Dhanpal R. Perioperative risk factors for pulmonary complications after non-cardiac surgery. J Anaesthesiol Clin Pharmacol. 2020 Jan-Mar;36(1):88-93. doi: 10.4103/joacp.

3. Abbott TEF, Fowler AJ, Pelosi P, Gama de Abreu M, Møller AM, Canet J, Creagh-Brown B, Mythen M, Gin T, Lalu MM, Futier E, Grocott MP, Schultz MJ, Pearse RM; StEP-COMPAC Group. A systematic review and consensus definitions for standardised end-points in perioperative medicine: pulmonary complications. Br J Anaesth. 2018 May;120(5):1066-1079. doi: 10.1016/j.bja.2018.02.007.

4. Sasaki N, Meyer MJ, Eikermann M. Postoperative respiratory muscle dysfunction: pathophysiology and preventive strategies. Anesthesiology. 2013 Apr;118(4):961-78. doi: 10.1097/ALN.0b013e318288834f. PMID: 23429163.

5. Miskovic A, Lumb AB. Postoperative pulmonary complications. Br JAnaesth. 2017 Mar 1;118(3):317-334. doi: 10.1093/bja/aex002.

6. Lumb AB. Pre-operative respiratory optimisation: an expert review. Anaesthesia. 2019 Jan;74 Suppl 1:43-48.

doi: 10.1111/anae.14508. 
7. Velicković J, Ladjević N, Milaković B, Likić-Ladjević I, Ugrinović D, Kalezić N. Preoperative evaluation of patients with history of allergy. Acta Chir Iugosl. 2011;58(2):177-83. doi: $10.2298 /$ aci1 $102177 \mathrm{v}$.

8. Tilak A, Ramirez AG, Turrentine FE, Sohn MW, Jones RS. Preoperative Gastroesophageal Reflux Disorder Is Associated With Increased Morbidity in Patients Undergoing Abdominal Surgery. J Surg Res. 2018 Dec;232:587-594. doi: 10.1016/j.jss.2018.07.051

9. Jammer I, Wickboldt N, Sander M, Smith A, Schultz MJ, Pelosi P, Leva B, Rhodes A, Hoeft A, Walder B, Chew MS, Pearse RM; European Society of Anaesthesiology (ESA) and the European Society of Intensive Care Medicine (ESICM); European Society of Anaesthesiology; European Society of Intensive Care Medicine. Standards for definitions and use of outcome measures for clinical effectiveness research in perioperative medicine: European Perioperative Clinical Outcome (EPCO) definitions: a statement from the ESA-ESICM joint taskforce on perioperative outcome measures. Eur J Anaesthesiol. 2015 Feb;32(2):88-105. doi: 10.1097/EJA.0000000000000118.

10. Özkan M, Kırkıl G, Dilektaşlı AG, Söğüt A, Sertoğullarından B, Çetinkaya E, Coşkun F, Ulubay G, Yüksel H, Sezer M, Özbudak Ö, Ulaşı1 SS, Arslan S, Kovan T. Summary of Consensus Report on Preoperative Evaluation. Turk Thorac J. 2015 Jan;16(1):4352. doi: 10.5152/ttd.2014.4505. Epub 2015 Jan 1.

11.Patwa A, Shah A. Anatomy and physiology of respiratory system relevant to anaesthesia. Indian J Anaesth. 2015 Sep;59(9):53341. doi: 10.4103/0019-5049.165849.

12.Ntima NO, Lumb AB. Pulmonary function tests in anaesthetic practice. BJA Educ. 2019 Jul;19(7):206-211. doi: 10.1016/j.bjae.2019.02.001. Epub 2019 Mar 26. PMID: 33456892; PMCID: PMC7807994.

13.Bevacqua BK. Pre-operative pulmonary evaluation in the patient with suspected respiratory disease. Indian J Anaesth. 2015 Sep;59(9):542-9. doi: 10.4103/0019-5049.165854.

14.Degani-Costa LH, Faresin SM, dos Reis Falcão LF. Preoperative evaluation of the patient with pulmonary disease. Braz J Anesthesiol. 2014 Jan-Feb;64(1):22-34.

doi: 10.1016/j.bjane.2012.11.002.

15. Wahr JA, Abernathy JH 3rd, Lazarra EH, Keebler JR, Wall MH, Lynch I, Wolfe R, Cooper RL. Medication safety in the operating room: literature and expert-based recommendations. Br J Anaesth. 2017 Jan;118(1):32-43. doi: 10.1093/bja/aew379.

16.National Guideline Centre (UK). Preoperative Tests (Update): Routine Preoperative Tests for Elective Surgery. London: National Institute for Health and Care Excellence (UK); 2016 Apr. PMID: 27077168.

17.Global Initiative for Chronic Obstructive Lung Disease. Global Strategy for the Diagnosis, Management, and Prevention of Chronic Obstructive Pulmonary Disease. 2019. https://goldcopd.org/wp-content/uploads/2018/11/GOLD-2019v1.7-FINAL-14Nov2018-WMS.pdf Date last accessed: March 25, 2019 .

18. Odor PM, Bampoe S, Gilhooly D, Creagh-Brown B, Moonesinghe SR. Perioperative interventions for prevention of postoperative pulmonary complications: systematic review and meta-analysis. BMJ. 2020 Mar 11;368:m540. doi: 10.1136/bmj.m540.

19. Canet J, Gallart L, Gomar C, Paluzie G, Vallès J, Castillo J, Sabaté S, Mazo V, Briones Z, Sanchis J; ARISCAT Group. Prediction of postoperative pulmonary complications in a population-based surgical cohort. Anesthesiology. 2010 Dec;113(6):1338-50. doi: 10.1097/ALN.0b013e3181fc6e0a.

20.Jamali, S., Dagher, M., Bilani, N., Mailhac, A., Habbal, M., Zeineldine, S., \& Tamim, H. (2018). The Effect of Preoperative Pneumonia on Postsurgical Mortality and Morbidity: A NSQIP Analysis. World Journal of Surgery, 42(9), 2763-2772. doi:10.1007/s00268-018-4539-4

21.Jonathan L. Benumof; Laryngeal Mask Airway and the ASA Difficult Airway Algorithm. Anesthesiology 1996; 84:686-699. https://doi.org/10.1097/00000542-199603000-00024

22.Lawal I, Bakari AG. Reactive airway and anaesthesia: challenge to the anaesthetist and the way forward. Afr Health Sci. 2009 Sep;9(3):167-9. PMID: 20589145; PMCID: PMC2887028.

23.Bui N, Coetzer M, Schenning KJ, O'Glasser AY. Preparing previously COVID-19-positive patients for elective surgery: a framework for preoperative evaluation. Perioper Med (Lond). 2021 Jan 7;10(1):1. doi: 10.1186/s13741-020-00172-2.

24.American Society of Anesthesiologists and Anesthesia Patient Safety Foundation Joint Statement on Elective Surgery and Anesthesia for Patients after COVID-19 Infection [updated 2020 December 8, 2020; cited 2020 March 16]. Available from: https://www.apsf.org/news-updates/asa-and-apsf-jointstatement-on-perioperative-testing-for-the-covid-19-virus/

25.Coccolini, F., Perrone, G., Chiarugi, M. et al. Surgery in COVID19 patients: operational directives. World J Emerg Surg 15, 25 (2020). doi: 10.1186/s13017-020-00307-2

26.Ke CC, Lin CS, Yeh CC, Chung CL, Hung CJ, Liao CC, Chen TL. Adverse Outcomes after Non-Chest Surgeries in Patients with Pulmonary Tuberculosis: A Nationwide Study. PLoS One. 2015 Jul 14;10(7):e0133064. doi: 10.1371/journal.pone.0133064.

27.National manual for Tuberculosis Control. 3rd ed. Health information Management Unit, National Programme for Tuberculosis Control and Chest Diseases. 2016. ISBN 978-9550742-07-3

28. Weingarten TN, Kor DJ, Gali B, Sprung J. Predicting postoperative pulmonary complications in high-risk populations. Curr Opin Anaesthesiol. 2013;26(2):116-125. doi:10.1097/ACO.0b013e32835e21d 2

29.Memtsoudis S, Liu SS, Ma Y, Chiu YL, Walz JM, Gaber-Baylis LK, Mazumdar M. Perioperative pulmonary outcomes in patients with sleep apnea after noncardiac surgery. Anesth Analg. 2011 Jan;112(1):113-21. doi: 10.1213/ANE.0b013e3182009abf.

30.Kaw R, Pasupuleti V, Walker E, Ramaswamy A, FoldvarySchafer N. Postoperative complications in patients with obstructive sleep apnea. Chest. 2012 Feb;141(2):436-441. doi: 10.1378/chest.11-0283.

31.Members of the Working Party, Nightingale CE, Margarson MP, Shearer E, Redman JW, Lucas DN, Cousins JM, Fox WT, Kennedy NJ, Venn PJ, Skues M, Gabbott D, Misra U, Pandit JJ, Popat MT, Griffiths R; Association of Anaesthetists of Great Britain; Ireland Society for Obesity and Bariatric Anaesthesia. Peri-operative management of the obese surgical patient 2015: Association of Anaesthetists of Great Britain and Ireland Society 
for Obesity and Bariatric Anaesthesia. Anaesthesia. 2015 Jul;70(7):859-76. doi: 10.1111/anae.13101.

32.Jabbour SA. Steroids and the surgical patient. Med Clin North Am. 2001 Sep;85(5):1311-7. doi: 10.1016/s00257125(05)70379-5.

33.Liu MM, Reidy AB, Saatee S, Collard CD. Perioperative Steroid Management: Approaches Based on Current Evidence. Anesthesiology. 2017 Jul;127(1):166-172. doi: 10.1097/ALN.0000000000001659.
34.Woodcock T, Barker P, Daniel S, Fletcher S, Wass JAH, Tomlinson JW, Misra U, Dattani M, Arlt W, Vercueil A. Guidelines for the management of glucocorticoids during the peri-operative period for patients with adrenal insufficiency: Guidelines from the Association of Anaesthetists, the Royal College of Physicians and the Society for Endocrinology UK. Anaesthesia. 2020 May;75(5):654-663. doi: 10.1111/anae.14963. Epub 2020 Feb 3. Erratum in: Anaesthesia. 2020 Sep;75(9):1252. PMID: 32017012. 